\title{
LA REPITENCIA ESCOLAR EN ESCUELAS PRIMARIAS DE SAN MIGUEL DE TUCUMÁN. UNA APROXIMACIÓN DESDE LAS REPRESENTACIONES SOCIALES Y LAS RELACIONES ENTRE DOCENTES Y ESTUDIANTES REPITENTES
}

GRADE REPETITION IN PRIMARY SCHOOLS OF SAN MIGUEL DE TUCUMÁN. AN APPROACH FROM TEACHER'S AND GRADE REPEATING PUPIL'S SOCIAL REPRESENTATIONS AND RELATIONSHIPS

Volumen 11, Número 1

pp. 1-36

Este número se publicó el 30 de abril de 2011

María Micaela Villalonga Penna

La revista está indexada en los directorios:

LATINDEX $, \underline{\text { REDALYC}}, \underline{\text { IRESIE}}, \underline{\text { CLASE}}, \underline{\text { DIALNET, DOAJ, E-REVIST@S}}$

La revista está incluida en los sitios:

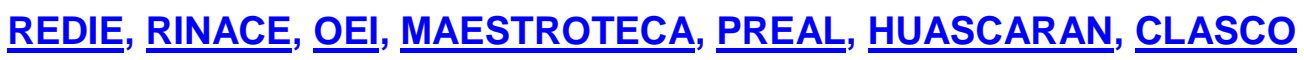




\title{
LA REPITENCIA ESCOLAR EN ESCUELAS PRIMARIAS DE SAN MIGUEL DE TUCUMÁN. UNA APROXIMACIÓN DESDE LAS REPRESENTACIONES SOCIALES Y LAS RELACIONES ENTRE DOCENTES Y ESTUDIANTES REPITENTES

\author{
GRADE REPETITION IN PRIMARY SCHOOLS OF SAN MIGUEL DE TUCUMÁN. AN \\ APPROACH FROM TEACHER'S AND GRADE REPEATING PUPIL'S SOCIAL \\ REPRESENTATIONS AND RELATIONSHIPS
}

\begin{abstract}
María Micaela Villalonga Penna ${ }^{\top}$
Resumen: Este artículo presenta resultados de investigación sobre las representaciones sociales de docentes y estudiantes repitentes acerca de la repitencia, y sus implicaciones en las relaciones entre estos actores educativos. La metodología utilizada fue de tipo cualitativo. Se realizaron entrevistas en profundidad a docentes y a estudiantes repitentes de primer grado, y observaciones participantes en escuelas de San Miguel de Tucumán. El análisis de los datos se efectuó acorde a la teoría fundamentada. Se identificaron categorías y temas en las entrevistas y observaciones participantes, y se triangularon los datos para elaborar una teoría explicativa del fenómeno. Los resultados mostraron que las representaciones docentes inciden en la conformación de las representaciones de los niños repitentes y en las relaciones áulicas. Las docentes, que definieron a la educación de manera unicausal, se manifestaron favorables a la repitencia. Los estudiantes repitentes se representaron negativamente a la repitencia y a los vínculos con docentes y pares. Las interacciones áulicas evidenciaron comunicaciones unidireccionales y una aplicación desigual de normas. Esto permitía a las docentes mantener una autoimagen satisfactoria, pero influía negativamente en la de los niños repitentes. Las docentes que consideraron a la educación como un proceso complejo, definieron a la repitencia como una situación desfavorable. Las representaciones de los alumnos repitentes sobre la repitencia y las relaciones con docentes y pares aunaron aspectos negativos y positivos. Las relaciones áulicas evidenciaron comunicaciones uni y multi-direccionales y una aplicación de normas más equitativa. La autoimagen de las docentes y de los niños repitentes contenía aspectos positivos y negativos.
\end{abstract}

\section{Palabras clave: REPRESENTACIONES, REPITENCIA, RELACIONES AULICAS, ARGENTINA}

\begin{abstract}
This paper presents research results on teacher's and grade repeating children's representations of grade repetition, and its implications for the relationships between them. The applied methodology was of qualitative type. Interviews in depth were held with first grade teachers and grade repeating pupils, as well as participant observations. Both of them took place in San Miguel de Tucuman's schools. The analysis of the information was carried according to the based emergent theory. Categories and themes were identified, triangulated in order to build a theory about the phenomenon. The results showed that teachers' representations affect the construction of grade repeating children's own representations and classroom relationships. Teachers who defined education in a unicausal way, evinced a favorable attitude towards grade repetition. Grade repeating pupils had negative representations about grade repetition and relationships with teachers and peers. Classroom interactions showed unidirectional communications and slightly unequal application of the rules. This allowed teachers to hold a satisfactory self-image, but it had a negative influence on the grade repeating children. Teachers that considered education a complex process defined grade repetition as an unfavorable situation. Grade repeating pupils' representations of grade repetition and relationships with teachers and classmates, included both negative and positive aspects. Classroom interactions showed uni and multi - directional communications and a more equitable application of rules. Teachers' and grade repeating children self- images included positive and negative aspects.
\end{abstract}

Key words: GRADE REPETITION, REPRESENTATIONS, CLASSROOM RELATIONSHIPS, ARGENTINA

\footnotetext{
${ }^{1}$ Licenciada en Psicología por la Universidad Nacional de Tucumán. Becaria del Consejo de Investigaciones de la Universidad Nacional de Tucumán (período 2009/2010). Integrante del Proyecto de Investigación: "La violencia/convivencia en escenarios escolares". Maestranda en Psicología Cognitiva y Aprendizaje por la Facultad Latinoamericana de Ciencias Sociales.
}

Dirección electrónica: micavillalonga@yahoo.com.ar

Artículo recibido: 10 de febrero, 2011

Aprobado: 28 de marzo, 2011 


\section{Introducción}

Los estudios estadísticos encarados por el Ministerio de Educación de la Nación y por el Ministerio de Educación de la Provincia de Tucumán muestran que la repitencia escolar constituye una problemática que posee vigencia en el sistema educativo y que se asocia a fenómenos como: la sobreedad, el abandono escolar y las carencias económicas. Si bien estos datos permiten dimensionar el impacto de esta problemática a nivel del sistema educativo, no posibilitan vislumbrar la incidencia del fenómeno en las relaciones entre los actores educativos. A este respecto, los enfoques teóricos que privilegian la noción de representación social resultan pertinentes, ya que han tratado la influencia de los conocimientos prácticos en los comportamientos de los sujetos. De esta forma, el problema a abordar en este trabajo se refiere a las implicancias que poseen las representaciones de los docentes y de los alumnos repitentes acerca de la repitencia, en las relaciones áulicas.

En la Argentina la investigación sobre esta problemática se ha desplegado a partir de estudios principalmente descriptivos. Diversos autores consideraron a la repitencia escolar, especialmente la del primer grado de la escolaridad primaria, como una experiencia negativa y difícil de revertir que pone en riesgo las trayectorias escolares de los niños (Farías, Fiol, Kit y Melgar, 2007; Maddonni y Aizecang, 2000). En el año 2006, datos de la Dirección Nacional de Información y Evaluación de la Calidad Educativa (DINIECE, 2008) indicaron que la tasa nacional de repitencia era del 6,60\%, la de sobreedad de 1,60\% y la de deserción escolar de 1,72\%. En el período 2007-2008, la provincia de Tucumán presentó una tasa de repitencia de $4,70 \%$, de sobreedad de $18,91 \%$ y de abandono interanual de 1,66\%. En el ciclo 2008-2009, la tasa de repitencia fue de $4,51 \%$, la de sobreedad de $17,24 \%$ y la de abandono interanual de 1,42\%. En el 2009-2010, la tasa de repitencia de $3,28 \%$, de sobreedad de $15,87 \%$ y de abandono escolar de $0,96 \%$ (Departamento de Planeamiento y Estadística, Ministerio de Educación de Tucumán-DEPMETUC-, 2010).

$\mathrm{Si}$ bien se aprecia una disminución en las tasas de repitencia, de sobreedad y de abandono interanual, cabe señalar que estas mejoras no se corresponden necesariamente con mejoras a nivel de alfabetización. El Operativo Nacional de Evaluación Educativa 2007 mostró que en la región NOA, en escuelas urbanas, el $35,2 \%$ de los niños evaluados en lengua, que cursaban primer, segundo y tercer grado (edad promedio: 6-9 años) presentaron un bajo desempeño (DINIECE, 2007). Además, en particular, en el año 2007, San Miguel de Tucumán tenía una de las tasas más altas de repitencia en escolaridad primaria de la provincia $(4,98 \%)$, 
siendo que un $9 \%$ de los alumnos se inscribían como repitentes en $1^{\circ}$ grado, un $8 \%$ en $2^{\circ}$, un $7,5 \%$ en $3^{\circ}$ y un $5,9 \%$ en $4^{\circ}$. Otros departamentos de la provincia con altas tasas de repitencia fueron Famaillá (8,99\%), Alberdi (8,52\%) y Trancas (7,78\%) (DEPMETUC, 2010).

En conjunto y como ya fuera indicado, estos datos muestran la vigencia de la repitencia en nuestro sistema educativo. Siguiendo a Perazza (2009), puede pensarse que los datos antes presentados ponen en evidencia años de escolaridad en los que los sujetos han permanecido invisibilizados en el sistema. En este sentido, si bien desde los datos estadísticos se aprecian mejorías en las tasas de repitencia, sobreedad y abandono interanual; vale retomar lo propuesto por Perazza (2009), a saber, una serie de situaciones que permanecen ocultas: los alumnos continúan inscriptos, van a la escuela con cierta frecuencia, realizan algunas de las actividades escolares, en ocasiones no estudian, y a simple vista pareciera que las consecuencias de no hacerlo no les resultan importantes.

Si bien y como se señaló, estos datos manifiestan las dificultades del sistema educativo provincial para garantizar las trayectorias escolares, no dan cuenta de sus implicancias en la vida en el aula ni los significados que los actores educativos le atribuyen (Kaplan, 2008; Pérez Gómez y Gimeno Sacristán, 1998). Al respecto, la propuesta de Morin (1997) acerca de la complejidad inherente a la educación posibilita entender a la repitencia como un fenómeno complejo en el que coexisten múltiples aspectos, algunos más visibles, como lo exponen las estadísticas y, otros más ocultos, referidos a la producción de significaciones por parte de los actores educativos y sus consecuencias en las relaciones áulicas. Acerca de esto último, los enfoques psicosociológicos resultan relevantes, ya que ponderan los estudios centrados en las representaciones recíprocas entre maestros y alumnos y, cómo éstas determinan las relaciones entre los docentes y los alumnos y de los pares entre sí (Gilly, 1986; Gilly, 2002; Jodelet, 1984; Schlemenson, 1996).

Cabe señalar que los enfoques psico-sociológicos se apoyan en la noción de Representaciones Sociales, las cuales han sido definidas como: imágenes que condensan significados; sistemas de referencia para comprender el entorno y lo novedoso; teorías para explicar los hechos, categorías para clasificar fenómenos, individuos y circunstancias o todo los antes mencionado a la vez. Se refieren al conocimiento ingenuo o de sentido común que se construye a partir de experiencias, informaciones, y modelos de pensamiento que son recibidos y transmitidos a través de la comunicación. Se trata de un conocimiento práctico, cuya finalidad 
es posibilitar la comunicación, la comprensión y el dominio del entorno social, material e ideal (Jodelet, 1984).

En esta dirección, los aportes de Postic (2000) destacaron la relación existente entre las representaciones y las relaciones educativas -las relaciones sociales que se establecen entre docentes y alumnos para el cumplimiento de objetivos educativos en una institución-. Las representaciones recíprocas que se forman los actores educativos, como plantea Postic (2000), determinan las modalidades de comunicación, la construcción de normas explícitas e implícitas, las expectativas recíprocas, los estatus asignados y el juego de reforzamientos o sanciones positivas y negativas en las prácticas educativas (Postic, 2000).

En la misma línea, Kaplan (2008) y Tenti Fanfani (2004) propusieron que en la relación docente-alumno, se verifica una asimetría de poderes a favor del enseñante, lo cual incrementa sus posibilidades de incidir y construir a los aprendientes. Las representaciones docentes han sido consideradas como elementos que, por un lado, permiten estructurar el entorno físicosocial, situarse y orientarse en éste y, por el otro, determinan las expectativas, las modalidades de vinculación y la conformación de la autoimagen de los sujetos educativos (Castorina y Kaplan, 2003; Kaplan, 1997; Kaplan, 2008; Postic, 2000; Tenti Fanfani, 2004). Así, cuando un niño es "etiquetado" o "rotulado" de un modo, se esperarán o no de él determinadas cosas y esto puede dificultar su acceso a otro estado diferente de aquel en el cual se encuentra (Postic, 2000).

Además, las representaciones que los docentes se forman acerca de sus alumnos determinan las sanciones positivas o negativas hacia las intervenciones espontáneas y solicitadas de determinados aprendientes; las comunicaciones unidireccionales basadas en intervenciones predominantemente cerradas (docente pregunta-alumno responde) o las comunicaciones multidireccionales; la estructuración de normas formales o explícitas y de normas informales o implícitas en las interacciones. En tanto el docente es capaz de anticiparse a la respuesta de sus alumnos, el funcionamiento mismo de la relación puede facilitarle la selección de aquellos que responderán correctamente, permitiéndole así mantener su imagen de "buen enseñante" (Perrenoud, 1996; Postic, 2000).

Asimismo, diversos autores han coincidido en considerar que los juicios de excelencia y los de fracaso son representaciones socialmente construidas que se constituyen en "la realidad" para los sujetos educativos, al ser legitimadas por las instituciones educativas (Kaplan, 2008; Perrenoud, 1996; Tenti Fanfani, 2004). Desde esta perspectiva, la excelencia y el fracaso 
escolar no son características intrínsecas de las conductas humanas, sino que suponen que determinadas conductas se relacionen con una norma y sean clasificadas en función de la misma. Esta relación se produce en la mente de las personas y depende de su representación de las conductas, de su interpretación de las normas y del marco en el cual se desenvuelven sus interacciones sociales. Cabe considerar también que las categorizaciones que un docente hace de sus alumnos pueden tener consecuencias en la historia personal del niño y en sus trayectorias escolares, porque el alumno construye su identidad bajo la mirada del maestro y de los compañeros (Gilly, 2002; Kaplan y Kantarovich, 2005; Postic, 2000).

Como fue indicado con anterioridad, los alumnos se forman una imagen de su docente y del grupo de pares y desean ser reconocidos y aceptados por éstos. Postic (2000) plantea que los aprendientes son sensibles a los signos verbales y no verbales transmitidos por el enseñante y por sus pares, a las intervenciones que son ponderadas o rechazadas y a lo que se espera de ellos, lo cual incide en la conformación de la imagen de sí en relación a lo escolar. Cuando un niño recibe constantes reforzamientos negativos por parte de sus pares y del docente construye una autoimagen desfavorable (Perrenoud, 1996; Postic, 2000; Schlemenson, 1996).

Las representaciones alteran el lugar en el grupo de clase, los trabajos, la confianza asignada y el control que se ejerce sobre el niño. Tal como señala Perrenoud (1996), al ingresar en la escuela los niños aprenden el oficio de ser alumnos, aprenden a anticiparse y responder en función de las expectativas de sus docentes y de sus pares, las diferencias existentes entre pares y que lo propio no es lo único existente. En el aula se esboza una compleja tarea que consiste en confrontar lo propio con lo ajeno, para rediseñar lo propio y bosquejar un proyecto posible que actúe como guía e incentivo para la construcción de conocimientos. Ser marginado o fracasar representa un estigma, ya que el fracaso se transforma en una marca de inadecuación social difícil de superar que afecta negativamente las relaciones educativas y las trayectorias escolares (Perrenoud, 1996; Postic, 2000; Schlemenson, 1996).

Teniendo en cuenta las consideraciones teóricas antes presentadas, cabe preguntar ¿cómo se representan y definen este fenómeno las docentes y los alumnos repitentes?, ¿cómo incide el rótulo de "alumno repitente" a nivel de las expectativas de sus docentes y de sus pares?, ¿y en la relación docente-alumno repitente y pares-alumno repitente?, ¿cómo perciben las docentes las relaciones entre los niños repitentes y sus pares?, ¿cómo se representan los niños el hecho de repetir?, ¿qué lugar creen ocupar estos niños para sus docentes y sus 
pares?, ¿cómo incide el rótulo "alumno repitente" en la imagen de sí de estos niños?. De este modo, los propósitos centrales de este trabajo son: a) reconstruir las representaciones de los docentes y de los alumnos acerca de la repitencia y b) describir la incidencia de las representaciones de las docentes y de los alumnos en la configuración de las relaciones áulicas.

\section{Metodología}

A fin de conocer los significados que las personas asignan a sus experiencias, se optó por un abordaje metodológico cualitativo. El muestreo fue de tipo teórico, ya que se seleccionaron sujetos que pudieran contribuir a la comprensión del fenómeno estudiado. Asimismo, la recolección de los datos y la teoría emergente fueron guiando la conformación de la muestra (Hernández Sampieri, Fernández Collado y Baptista Lucio, 2000).

Participaron 8 maestras de $1^{\circ}$ grado $^{2}$ (2 con 6 años de experiencia, 1 con 7 años y 1 con diez años) y 10 niños repitentes (7 con 3 años de sobreedad -9 años de edad- y 3 con 2 años de sobreedad -8 años de edad-). Las docentes y los alumnos pertenecían a dos escuelas de la periferia de San Miguel de Tucumán (ciudad capital de la provincia de Tucumán). La obtención de información se efectuó a partir de entrevistas en profundidad a docentes y a niños repitentes: se realizaron 3 entrevistas en profundidad a cada una de las docentes con una duración de 60 minutos cada una, y 2 entrevistas a cada uno de los niños repitentes con una duración de 40 minutos cada una.

También, se realizaron 3 observaciones participantes de clase en cada uno de los cuatro grados, para obtener información sobre los comportamientos y las relaciones entre los actores educativos. La estancia total en el campo fue de sesenta días hábiles en cada institución educativa. Tanto las entrevistas en profundidad como las observaciones participantes se llevaron a cabo de mayo a julio de 2010.

Este estudio se basó en los lineamientos de la teoría fundamentada de tipo emergente, por lo que la construcción de la teoría que da cuenta del fenómeno se dio a partir de los datos (Hernández Sampieri, Fernández Collado y Baptista Lucio, 2000). Luego de realizar las primeras entrevistas a las docentes, se procedió a analizarlas buscando categorías

2 El $1^{\circ}$ grado es el curso más bajo de la escolaridad primaria o elemental del Sistema Educativo Argentino. Volumen 11, Número 1, Año 2011, ISSN 1409-4703 
preliminares. A partir de estos datos, se seleccionaron a los niños repitentes y se los entrevistó procediendo de manera similar.

Posteriormente, se efectuaron la segunda y la tercera entrevista a docentes y la segunda entrevista a niños repitentes, refinando cada vez más la búsqueda de categorías, hasta llegar a la saturación. Para ello, se utilizó la estrategia de comparación constante, que posibilitó extraer las representaciones reiterativas en el discurso. Finalizadas las entrevistas, se realizaron las primeras observaciones participantes de clase y, en función de la identificación de categorías analíticas preliminares, se efectuaron las observaciones restantes, refinando la búsqueda de categorías por comparación.

Finalmente, se identificaron temas generales en las entrevistas en profundidad y en las observaciones participantes y, a partir del proceso de triangulación entre ellos, se generaron hipótesis que permitieran construir una explicación del fenómeno de la repitencia (Hernández Sampieri, Fernández Collado y Baptista Lucio, 2000). Los temas y categorías encontradas se sometieron al juicio de dos expertos en la cuestión externos a esta investigación.

\section{Resultados}

Se presentan, a continuación, los temas y las categorías comprendidas en éstos, encontrados en las entrevistas en profundidad a docentes y a niños repitentes:

1-Representaciones docentes sobre la educación: enunciados sobre el enseñar y el aprender, aspectos que involucran, contextos en que sucede, representaciones sobre el rol docente y sobre el rol de alumno.

2-Representaciones de docentes y de alumnos sobre la repitencia: descripciones de las docentes acerca de la repitencia en tanto procedimiento, sobre sus causas y descripciones de los alumnos sobre el hecho de repetir.

3-Representaciones de los niños repitentes sobre lo escolar: caracterizaciones que hacen los niños repitentes de los aspectos ponderados y rechazados en relación a lo escolar.

4-Representaciones recíprocas docente-alumnos repitentes: adjetivaciones utilizadas por las docentes para referirse a los niños repitentes, estatus de los niños repitentes para sus docentes y adjetivaciones usadas por los niños repitentes para referirse a sus docentes. Incluye también qué esperan las docentes de los alumnos repitentes y cómo perciben éstos últimos dichas expectativas. 
5-Representaciones recíprocas docente-alumnos repitentes sobre su relación: caracterizaciones que hacen las docentes y los alumnos repitentes sobre su vínculo y descripciones de hechos de violencia en el mismo.

6-Representaciones de docentes y de alumnos repitentes sobre la relación entre pares: enunciaciones descriptivas realizadas por docentes y alumnos repitentes sobre los vínculos entre pares, dando cuenta también de hechos de violencia.

7-Representaciones de los alumnos repitentes sobre la imagen de sí en relación a lo escolar: descripciones sobre la imagen de sí que poseen los niños repitentes.

8-Representaciones de docentes y de alumnos repitentes sobre las comunicaciones en el aula: manifestaciones que dan cuenta de las imágenes de las docentes y de los niños repitentes sobre el tipo de intervenciones que son propiciadas o evitadas a partir de sanciones positivas o negativas.

9-Representaciones de docente y de alumnos repitentes sobre las normas: expresiones que permiten apreciar las imágenes que poseen las docentes y los alumnos repitentes acerca de las reglas explícitas e implícitas que regulan la vida en el aula y tipo de aplicación de las normativas.

En las observaciones participantes en contextos áulicos se identificaron los siguientes temas y categorías:

1-Organización del espacio áulico: referido al lugar del aula en el que se sientan los niños repitentes: cerca del escritorio de la docente, en la parte delantera del aula, en la parte de atrás del aula.

2-Modalidades de comunicación con el docente y de participación en clase de los niños repitentes: sobre las características que tienen las comunicaciones y los reforzamientos a las intervenciones en clase: modalidad unidireccional (docente pregunta- alumno responde), sanciones negativas y positivas a las intervenciones espontáneas de los niños repitentes, reforzamientos positivos a las intervenciones solicitadas a los niños repitentes, reforzamientos positivos a las intervenciones solicitadas de los "buenos alumnos", reforzamientos positivos y/o negativos a las intervenciones espontáneas de los "buenos alumnos".

3-Modalidades de comunicación en clase de los niños repitentes con los pares: acerca de la cooperación entre pares, sanciones negativas y/o positivas por parte de los pares 
a las intervenciones espontáneas de los niños repitentes, reforzamientos positivos por parte de los pares a las intervenciones solicitadas a los niños repitentes, reforzamientos positivos por parte de los pares a las intervenciones solicitadas a los "buenos alumnos" alumnos, reforzamientos positivos y/o negativos por parte de los pares a las intervenciones espontáneas de los "buenos alumnos".

4-Aplicación de las normas en clase: sobre la aplicación de las normas explícitas en clase a niños repitentes por mal comportamiento, la aplicación de las normas explícitas en clase a los pares por mal comportamiento, aplicación de normas implícitas (mirada fija, generalizaciones que particularizan, unidireccionalidad obligatoria en las interacciones) a niños repitentes por mal comportamiento, Aplicación de normas implícitas (mirada fija, generalizaciones que particularizan, unidireccionalidad obligatoria en las interacciones) al resto de los compañeros.

Las relaciones entre los diferentes temas permitieron identificar: dos grupos de docentes, que diferían sobre su concepción de la educación y sobre los aspectos vinculados a la misma y en sus comportamientos en el aula, y dos grupos de alumnos que diferían en su concepción sobre el hecho de repetir, sus consecuencias y sus comportamientos. Cabe señalar que los nombres usados para identificar a los enunciados de las docentes y de los alumnos son ficticios.

\section{- Representaciones docentes sobre la educación}

Las docentes del primer grupo se representan al enseñar y el aprender de una manera que puede describirse como causal o asociacionista (Farías et al., 2007; Gvirtz y Palamidessi, 2008). Una maestra señalaba: "Transmitir saberes a otros en la escuela, lo que se espera desde lo curricular y también valores. Enseñar es transmitir contenidos, valores, normas... Y que los chicos adquieran lo que se les transmite. Aprender es habituar a alguien para que haga algo, lo que enseña la escuela desde lo conceptual es importante pero también son importantísimos los límites, que respeten las reglas... Que se porten adecuadamente" (Lina, 10 años de docencia, 12 de marzo de 2010). Las causas de las fallas o del fracaso en la "transmisión-adquisición" de conocimientos, se atribuyen a las diferencias entre el contexto familiar y el contexto escolar, a las carencias económicas y a los problemas afectivos generados por situaciones familiares desfavorables: 
"A veces lo que saben es contradictorio con lo que nosotros queremos enseñarles (...) me da la impresión de que lo que traen de la casa va como a contramano de lo que se trata de enseñar aquí y es un problema (...) tienen necesidades básicas insatisfechas y a veces muchos problemas en la casa que traen problemas emocionales como separaciones de los padres" (Lina, 10 años de docencia, 19 de marzo de 2010).

Estas docentes proponen como un aspecto central de su rol la transmisión de información y como un elemento inherente al rol del alumno la recepción o adquisición pasiva de lo trasmitido por el docente, cuestión ésta que se ve determinada por el buen comportamiento y el compromiso familiar con lo escolar. En función de estos parámetros, establecen diferencias entre aquellos alumnos que llenan o no sus expectativas en relación con el rendimiento escolar, a las producciones escolares: "Algunos chicos son mejores alumnos que otros, tienen siempre la tarea prolija, con buena letra, el cuaderno completo, limpio; los padres se preocupan por ellos", y a lo que ellas consideran como buen comportamiento: "que se queden sentaditos y calladitos en su lugar y hagan la tarea que se les da, que no molesten a sus compañeros (...)" (Lina, 10 años de docencia, 19 de marzo de 2010).

Así, establecen distinciones dicotómicas del tipo buenos y malos alumnos (Postic, 1982; Farías et al., 2007; Perreneaud, 1996). Las representaciones de estas docentes, indican que buen alumno es el que logra adquirir los conocimientos transmitidos por la maestra y se comporta como el docente espera: "Algunos son buenos alumnos (...) se portan bien en clase $y$ hacen siempre la tarea" y mal alumno el que no se adecúa a las expectativas docentes: "Otros no son tan buenos, no tienen el cuaderno o lo tienen destruido, sucio, roto, incompleto... es como si no les importara a ellos ni a los padres lo que se hace aquí en la escuela y molestan mucho en clase, golpean a los compañeros, gritan, juegan" (Sabrina, 7 años de docencia, 7 de abril de 2010).

Las diferencias marcadas entre el contexto escolar y el contexto familiar se verían acentuadas por la desvalorización del trabajo docente por parte de las familias de los alumnos (Lacasa, 1994). Dicha desvalorización sería percibida como una forma de violencia simbólica que genera malestar en las docentes (Abramovay y Das Graças Rua, 2005). Al decir de una docente:

"Hoy en día la docencia está muy desvalorizada... Yo sé que la mitad de mis alumnos vienen para que los padres cobren los planes sociales $y$, hacerse respetar, que los chicos 
y los padres te respeten es muy difícil... los chicos no aprenden, porque en la casa no les importa lo escolar" (Clara, 7 años de docencia, 20 de abril de 2010).

En contraste, las docentes del segundo grupo proponen concepciones más complejas sobre el enseñar y el aprender, reconociendo diferentes factores implicados en estos procesos (emocionales, cognitivos, biológicos), la necesidad de que el aprendiente logre relacionar lo que fue transmitido por la docente con sus conocimientos previos, la importancia de que en la escuela se reconozcan los aprendizajes realizados en la familia. Remarcan también lo incalculable del enseñar, evidenciado en el hecho de que la transmisión no garantiza la aprehensión por parte del alumno (Alliaud y Antelo, 2006; García Márquez, 1986; Gil Moreno, 2008; Schlemenson, 1996). Una docente decía:

"Es formar como persona, no es enseñar simplemente lo que se espera para un grado sobre los contenidos, también valores (...). Tenés que ver qué es lo que ya saben los chicos (...) y a veces vos enseñás y no aprenden (...) y hay que ser responsable por los resultados (...); lo de aprender es complicado también porque entran en juego muchas cosas: Io emocional, si un chiquito tiene problemas en la casa eso le puede jugar en contra de los aprendizajes y de lo cognitivo, y lo biológico, si está desnutrido también se le pueden complicar las cosas... bueno para el que enseña creo que también vale esto que te decía ¿no? (...) se da toda la vida, no se termina (...)” (Ana, 6 años de docencia, 22 de marzo de 2010).

Las representaciones del oficio docente marcan las vicisitudes inherentes a la transmisión de conocimientos: " $Y$ sí, a veces pasa que el docente quiso enseñar y los chicos no aprendieron" (Alliaud y Antelo, 2006). Asimismo, las maestras señalan la posibilidad de aprender de sus alumnos, lo cual, desde la perspectiva de Alliaud y Antelo (2006), daría cuenta del reconocimiento de una carencia en sus conocimientos. Esto podría constituirse en una motivación para seguir aprendiendo y transmitir versiones del conocimiento que contemplen los intereses, fortalezas y fragilidades de sus aprendientes.

Tal como proponen los autores antes citados, sólo aquel que puede aprender es capaz de enseñar (Alliaud y Antelo, 2006). Al respecto, una docente decía: "Los chicos aprenden del docente, pero el docente también aprende de los alumnos (...) cuando los chicos no aprenden... aprendés que no has tenido en cuenta quiénes son tus alumnos, que saben y que 
no" (Paola, 6 años de docencia, 5 de abril de 2010). Marcan igualmente aspectos gratificantes sobre su tarea, lo cual implicaría la construcción de una imagen de sí, en la cual coexisten aspectos favorables y desfavorables:

"El docente marca la diferencia, que el chico vea que la escuela no está sólo para que el padre pueda cobrar el plan, que aquí hay cosas importantes que él puede aprender, (...) y es muy satisfactorio cuando ves que los chicos pueden leer o escribir" (Ana, 6 años de docencia, 22 de marzo de 2010).

El oficio de alumno se centra en el logro de aprendizajes referidos a lo curricular, considerando, para ello, la necesidad de que éstos relacionen lo que el docente presenta como objeto a conocer con lo que ya saben, a fin de que puedan darle un sentido. Esto situaría las concepciones de las docentes sobre el aprendizaje en una línea constructivista (Coll, 1996). Como proponía una docente:

"Bueno algo ya saben, distinto a lo que les ofrece la escuela y me cuesta capitalizar eso que ya traen, pero trato... es que yo presento algo nuevo, pero para que lo entiendan tienen que relacionarlo con algo... algo que sepan de antes... los chicos no son hojas en blanco" (Ana, 6 años de docencia, 20 de abril de 2010, 3 de mayo de 2010).

La consideración de los aprendizajes realizados en contextos informales no sólo facilitaría la consecución de los aprendizajes escolares, sino que, también, tendería a disminuir la distancia percibida por las enseñantes entre el contexto escolar y el familiar: "Cuando uno nombra en la clase cosas que ellos ya conocen las cosas se hacen más fáciles, como cuando trabajamos el cuento del pastor mentiroso y ellos contaban que decían en sus casas sobre mentir" (Carina, 6 años de docencia, 3 de mayo de 2010) (Lacasa, 1994; Schlemenson, 1996).

\section{- Representaciones de las docentes y de los alumnos repitentes sobre la repitencia}

Las docentes del primer grupo, se representan a la repitencia como un procedimiento beneficioso para el alumno y de carácter asociacionista, ya que, por la reiteración de las mismas ejercitaciones, permitiría la adquisición y/o reforzamiento de los conocimientos: "A veces es bueno que repitan porque al año siguiente logran aprender lo que no pudieron (...) pueden ejercitarse más y así aprenden" (Lina, 10 años de docencia, 12 de marzo de 2010). 
Esta forma de concebir a la repitencia se encuentra en la misma línea que las concepciones de educación, las cuales, como fue indicado, se basan en la transmisión-adquisición de conocimientos de forma lineal y mecánica (Farías et al., 2007; Gvirtz y Palamidessi, 2008).

Además, al situar las causas del repetir y del bajo rendimiento escolar en las carencias económicas y afectivo-familiares, las docentes se no involucran en las vicisitudes de la construcción de los conocimientos y sus problemáticas. Así, los niños y sus familias son situados como portadores de un problema, cuyas causas y posibles soluciones no implican a las enseñantes.

En contraste, los alumnos repitentes presentes en las aulas de estas docentes se representan a la repitencia como un hecho negativo, tanto en lo que respecta a las actividades escolares como en lo referido a las relaciones con los pares; al decir de uno de ellos: "Y mal, aburrido... Hay que ver de nuevo eso de la fecha y la canción del año pasado y los amigos ya son de otro grado y las burlas de los otros chicos" (Kevin, 9 años, 10 de mayo de 2010).

En cambio, para las docentes del segundo grupo, la repitencia constituye un procedimiento situacional y con consecuencias negativas para los niños; al respecto, una maestra señalaba:

"La situación de repetir marca una diferencia con los compañeros, si se dan cuenta de que algo no lograron (...). Yo no creo que sea bueno, que vayan a aprender más y mejor, se vuelven más inseguros. Hubo algo que la escuela no supo ofrecer, tal vez no he sabido cómo enseñar... O algo externo a la escuela como las situaciones familiares, y que jugaron en contra de las posibilidades de aprender de esos chicos" (Carina, 6 años de docencia, 12 de mayo de 2010).

Las causas de la repitencia, para estas enseñantes, involucran múltiples aspectos (económicos, familiares, afectivos, académicos), incluyendo los referidos a las estrategias docentes de enseñanza, lo cual indicaría cierta capacidad de reflexión sobre su propia práctica. A esto debe agregarse que estas docentes definen como un aspecto central de su rol la transmisión responsable de conocimientos: "si un chico repite hay que hacerse responsable por los resultados y no trasladar todo a la familia y la pobreza" (Nadia, 7 años, 21 de mayo). De este modo, en tanto se refieren a la repitencia de manera situacional, esto facilitaría un desplazamiento del problema hacia la problemática, hacia lo cuestionable y superable. 
Por su parte, las representaciones de los niños repitentes acerca de la repitencia, se sitúan en la misma línea que las representaciones de sus docentes. Para estos niños la repitencia constituye una situación con aspectos positivos y negativos referidos, principalmente, a las tareas escolares: "Y es más fácil, porque ya sé lo que hay que hacer y los compañeros me copia, $n$ pero... es fiero eso de hacer el mismo deber (...) jaburrido, aburrido!" (Nadia, 7 años, 21 de mayo de 2010).

\section{- Representaciones de los niños repitentes sobre lo escolar}

Las representaciones docentes sobre lo escolar parecen incidir en las representaciones de los niños repitentes. Los niños repitentes del primer grupo, describen a la escuela y las actividades escolares reiterativas con adjetivaciones negativas. Sobre la escuela proponen: "Fiero", no me salen los deberes y la seño grita y me reta (...) Fiero, no me gusta... la seño se enoja siempre, siempre conmigo" (Maira, 9 años). Al referirse a las tareas escolares, indican el carácter reiterativo y de corte asociacionista de las mismas: "me aburro, porque la tarea es fácil... Eso de la fecha y el día con el dibujito y la termino y me aburro y entonces molesto (...) hago lo mismo del año pasado y me aburro y repito las mismas cosas" (Francisco, 9 años, 28 de mayo de 2010).

Los niños repitentes del segundo grupo, en cambio, atribuyen aspectos positivos y negativos a lo escolar, en coincidencia con las representaciones sobre la educación de sus maestras: "Y más o menos (...) me gusta eso de la asistencia y cortar y pintar con los amigos con la plasticola del color (...) y eso de la fecha fiero, fiero y eso de quedarse en el asiento sin hacer nada" (María, 7 años, 4 de mayo de 2010).

\section{- Representaciones recíprocas docente-alumnos repitentes}

Si bien, las representaciones sobre los niños repitentes de las docentes del primer grupo, poseen connotaciones principalmente desfavorables (violentos, reflejo de su familia, indisciplinados, víctimas, apáticos, dolor de cabeza, causas perdidas), estas maestras expresan expectativas altas y de carácter positivo sobre el rendimiento escolar de estos niños: "espero que pasen de grado y que se lleven bien con sus compañeros" (Rita, 10 años de docencia, 16 de marzo de 2010). Sin embargo, cuando éstas no se ven cumplidas, la explicación recae en

3 Fiero: en referencia a lo feo o desagradable. Volumen 11, Número 1, Año 2011, ISSN 1409-4703 
los problemas familiares, en la precariedad de las condiciones de vida y en las reiteradas inasistencias, cuestiones que inciden negativamente en el rendimiento escolar:

"Los chicos no aprenden porque en la casa no les importa nada de lo que hacen en la escuela... también está el tema de la pobreza extrema en la que viven... y las inasistencias, faltan tanto que pierden clases sobre temas importantes y después es muy difícil que lleguen a nivelarse con el resto de los chicos... y empiezan a fallar mucho en el rendimiento, en especial en lengua" (Lina, 10 años de docencia, 19 de marzo de 2010).

Esto permite a las docentes deshacerse de la responsabilidad por los resultados del proceso de enseñanza y de aprendizaje (Postic, 1982). Las atribuciones docentes negativas parecen influir las representaciones de los niños repitentes sobre sus docentes, ya que las describen de manera predominantemente desfavorable: "Y mala, me grita y me agarra del brazo para que me quede y mia dejao ${ }^{4}$ sin recreo porque le he pegado a uno y... Gritona, gritona" (Agustín, 9 años, 8 de junio de 2010).

En contraste con lo señalado por las docentes, los niños repitentes perciben expectativas bajas y altas por parte de ellas, referidas a las tareas escolares y al comportamiento en clase:

"La seño se enoja porque no hago los deberes de la casa y porque ensucio el cuaderno, pero me dice que leo mejor que el año pasado y dice que quiere que pase de grado, que lea bien así paso (...) y dice que si me porto mal y no presto atención no aprendo y quedo" (Maira, 9 años, 4 de junio de 2010).

Aunque las representaciones sobre los niños repitentes presentes en las aulas de las docentes del segundo grupo, contemplan aspectos positivos (buenos chicos, desafío), los negativos (indisciplinados, apáticos, violentos) y las bajas expectativas resultan dominantes. Esto último derivaría de la multiplicidad de factores que incidirían en el enseñar y en el aprender y que contribuirían al establecimiento de diferencias entre los niños repitentes y sus pares: "yo espero que puedan aprender a leer, que puedan pasar, pero muchos ya vienen con una mala experiencia en la escuela, o tienen problemas en la casa, o de salud, hay mucho que juega en contra" (Esther, 7 años de docencia, 13 de abril de 2010). Resulta significativo el hecho de que,

4 Mia dejao: regionalismo para "me ha dejado". Volumen 11, Número 1, Año 2011, ISSN 1409-4703 
al valorar positivamente a los niños repitentes, los propongan como un desafío, un reto a las estrategias docentes de enseñanza, que motivaría la búsqueda de alternativas para superarlo y que resulta consonante con el involucramiento en las causas del repetir.

Los alumnos repitentes describen a estas docentes adjetivándolas, a la vez, favorable y desfavorablemente: "Es buena y mala (...) es buena cuando se ríe y nos hace cantar y mala cuando grita y grita y se enoja y dice que me porto pésimo molesto en la clase y no hago las tareas de la casa" (Nadia, 7 años, 24 de mayo de 2010). Estos niños perciben las altas y bajas expectativas depositadas por sus docentes, en relación con los aprendizajes estipulados curricularmente y, las altas expectativas, en relación a lo comportamental:

"La seño quiere que pase de grado y dice que hay que estar atento para aprender y que si molesto no aprendo (...) y que este año me porto mejor y que ya leo mejor, se pone contenta" (María, 7 años, 11 de mayo de 2010).

"Y a mí tres veces me ha puesto carita feliz y excelente $y \ldots$ Y se pone contenta, porque dice que es porque le presto atención y no ando molestando" (Francisco, 9 años, 28 de mayo de 2010).

\section{- Representaciones recíprocas sobre las relaciones docente-alumnos repitentes}

Las representaciones de las docentes del primer grupo acerca de su vínculo con los niños repitentes remarcan la bondad del mismo y, a la vez, la dependencia, como un elemento que aseguraría a estos niños llenar las expectativas docentes, incluyendo las referidas a los aprendizajes estipulados desde lo curricular. Una docente decía: "Tengo una buena relación con ellos y les dedico mucho tiempo y esfuerzo (...) Ellos son los que más me necesitan, son como los hijos que necesitan de su madre, y si yo no estoy pendiente no aprenden lo que tienen que aprender para pasar" (Sabrina, 7 años de docencia, 13 de abril de 2010).

En oposición con esto, en la relación con los alumnos, aprecian hechos de lo que ha sido denominado como violencia verbal y como violencia física (Abramovay, 2005; Debarbieux, 2001). Los alumnos son presentados como agresores y los hechos violentos como un aspecto significativo que obstruye las relaciones docente-alumno: "me gritan, no me respetan, me insultan a veces...Y así no se puede estar bien con ellos" (Lina, 10 años de docencia, 19 de marzo de 2010); "algunos chicos hasta llegaron a pegarme porque les he llamado la atención 
por el mal comportamiento" (Rita, 10 años de docencia, 24 de marzo de 2010). Sin embargo, la violencia es interpretada como una manifestación de comportamientos aprendidos en el hogar que se exteriorizan en la escuela, evitando así la referencia a la forma en la que se va configurando y desarrollando el vínculo docente- alumno repitente: "son así, reaccionan así porque es lo que aprendieron en la casa" (Lina, 10 años de docencia, 19 de marzo de 2010).

Por su parte, los niños repitentes atribuyen características negativas a su relación con las docentes: "Mal, mal... la seño me grita y dice que me quede quieta en el asiento y me grita" (Darío, 9 años, 10 de junio de 2010). También aluden a situaciones que generan malestar, en las cuales las docentes se sitúan como agresoras a nivel simbólico: "La seño no me da bolilla, yo diga la pregunta y no mira y hace que no escucha y le dice a Paula que ella diga y le dice que bien, porque ella es la buena alumna" (Kevin, 9 años, 17 de mayo de 2010), y físico: "Si no contesto grita que no la escuchamos y te agarra del brazo y te para mirando el pizarrón, y es feo y aburrido iy los chicos se ríen!" (Paola, 9 años, 11 de junio de 2010) (Abramovay, 2005; Debarbieux, 2001).

Los hechos de violencia dan lugar a situaciones en las que el grupo de pares termina sancionando negativamente a los niños repitentes, lo cual genera también malestar, ya que, como plantea Schlemenson (1996), los niños en la escuela buscan el reconocimiento del docente y de los pares, por lo que el rechazo se convierte en un signo de inadecuación difícil de tolerar y de superar.

En las representaciones de las docentes del segundo grupo sobre su relación con los niños repitentes se aprecia la coexistencia de aspectos positivos y negativos que poseen consecuencias a nivel comportamental. En el caso de la relación docente- alumnos repitentes perciben ciertas dificultades tanto por parte de los niños como de sí mismas, derivadas del rótulo "niño repitente". Así, una docente proponía:

"Mmm... Yo trato de no tener en mi mente que son repitentes, trato de no hacer diferencias..., pero es difícil, porque hay una diferencia (...) como que me da la impresión de que les cuesta más acerarse..., pero también puede ser que sea yo la que opone resistencia" (Sabrina, 7 años de docencia, 12 de abril de 2010).

Las dificultades, para estas docentes, derivan también de la violencia verbal de los niños hacia ellas, vista como una estrategia aprendida en el grupo familiar para lograr atraer la atención de los adultos. Estas enseñantes tendrían mayores posibilidades que las del primer 
grupo, para comprender los sentimientos y pensamientos de los niños. Sin embargo, ante las dificultades para dar una explicación acerca de las agresiones por parte de los aprendientes, sitúan las causas en un contexto ajeno al escolar: "es duro, a veces me cuesta creer que me griten... Que no me respeten, y esas son cosas que aprenden en la familia" (Ana, 6 años de docencia, 20 de abril de 2010).

En la misma dirección, los alumnos repitentes proponen también aspectos positivos y negativos en la relación docente-alumno; una alumna comentaba: "con la seño me llevo bien..., pero me reta porque no hago las tareas de la casa y charlo en la clase con los amigos y me dice que eso es molestar y les pego en la clase a los que molestan" (María, 7 años, 4 de mayo de 2010); otro niño decía: "más o menos (hace el gesto con la mano) es gritona, dice que me porto pésimo porque me pelio ${ }^{5}$ con los otros chicos y que molesto en la clase" (Francisco, 9 años, 28 de mayo de 2010).

También describen hechos de violencia verbal y silenciosa: "la seño grita y grita cuando se portamos mal... y mucho (se tapa las orejas) y es molesto (...) y no me presta atención cuando yo digo la pregunta, no me mira" (Nadia, 7 años, 21 de mayo de 2010) (Abramovay, 2005). En este caso se aprecia, además, la importancia de la mirada del docente como medio de subjetivación, de reconocimiento o desconocimiento, de autorización o desautorización dirigido hacia los niños repitentes (Abramovay, 2005; Debarbieux, 2001; Kaplan y Kantarovich, 2005).

- Representaciones de las docentes y de los alumnos repitentes sobre la relación con los pares

En las representaciones de las docentes del primer grupo sobre la relación de los niños repitentes con sus pares, se aprecia la confluencia de aspectos favorables y desfavorables ya que, por un lado, remarcan las situaciones de cooperación entre pares: "Se llevan bien con los chicos del grado, se dejan ayudar y ayudan a los compañeros, se prestan las cosas y juegan en los recreos" y, por el otro, señalan la existencia de violencia verbal y física como un impedimento para la construcción de vínculos (Abramovay, 2005; Debarbieux, 2001). Una docente planteaba: "A veces hay peleas y algunos les hacen burla, algunos son agresivos,

5 Pelio: referido al verbo pelear. Volumen 11, Número 1, Año 2011, ISSN 1409-4703 
patean y golpean a sus compañeros y se llevan mal" (Isabel, 10 años de docencia, 16 de marzo de 2010).

Las representaciones de los niños repitentes sobre su relación con los pares, incluyen aspectos positivos y negativos, predominando éstos últimos: "bieeen... bueno, más o menos... Me pelio con Raúl y con Tito porque se burlan y me dicen que soy (se toca la cabeza) así... duro... porque no entiendo bien lo que enseña la seño... y yo los mato en el recreo" (Agustín, 9 años, 8 de junio de 2010).

Indican también la existencia de hechos de violencia física, en los que se sitúan principalmente como agresores: "Ios patio a los varones y corro adentro del grado y les molesto a los compañeros y les pego con el cuaderno (...) con el libro se pegamos y los golpio ${ }^{6}$ y los patio para que se amansen" (Maira, 9 años, 4 de junio de 2010) y, secundariamente como víctimas del maltrato, posición genera malestar: "no me gusta que me peguen y si no pegás te pegan más y feo" (Kevin, 9 años, 17 de mayo de 2010).

Además, perciben las bajas expectativas que les atribuyen sus pares; al decir de dos niños: "Que no tengo que ensuciar el cuaderno y que medio improlijo con las fotocopias y la voligoma ${ }^{7}$ se me mancha todo" (Paola, 9 años); "Y que me porto mal y por eso me reta la seño y grita y grita y si digo mal la pregunta o no la sé se ríen" (José, 7 años, 10 de junio de 2010).

En las representaciones de las docentes del segundo grupo acerca del vínculo de los niños repitentes con los pares, coexisten aspectos positivos y negativos. Sobre los primeros señalan la buena relación que tienen estos niños con sus compañeros y en relación a los segundos indican la violencia entre los niños. Dos docentes comentaban:

"Algunos son tranquilos (...) charlan con los compañeros y juegan en el recreo, pero nunca con agresividad, son más calladitos, a lo mejor algo tímidos porque les da vergüenza repetir" (Carina, 6 años de docencia); "Algunos chicos son violentos, les pegan y los insultan a los compañeros... pero lo peor es cuando son víctimas, quedan minimizados" (Esther, 7 años de docencia, 13 de abril de 2010).

Resulta significativo el hecho de que las docentes noten la necesidad de reconocimiento de los niños repitentes por parte de los pares, ya que esto daría cuenta de sus posibilidades de anticipación a los intereses de los niños: "A ellos también les importa que los integren, que los 
reconozcan los otros chicos, que no se burlen... Ya sé que hay una diferencia porque ellos repiten... Pero que no se sientan excluidos" (Paola, 6 años de docencia, 20 de abril de 2010).

Los niños repitentes del segundo grupo se representan su relación con los compañeros de clase de manera positiva y negativa a la vez: “Bien! Mauricio, Tapia y Anahí, charlamos y jugamos en el recreo a la pilladita y leemos la consigna en clase y Anahí me presta los colores para el sol y me ayudan a leer el pizarrón porque la seño les pide... Y si me peleo, por eso de molestar y quitarle las cosas a los amigos" (Rocío, 9 años, 20 de mayo de 2010).

A diferencia del grupo anterior, estos niños señalan la existencia de hechos de violencia verbal y física entre pares, siendo que, generalmente, la primera da lugar a la segunda y que los niños se sitúan como agresores y como víctimas. Dos niños decían: "si me dicen tonto los patio y en el recreo los patio más" (Darío, 9 años, 14 de junio de 2010); "Brian me dice tonta y me pega y la seño lo reta y no hace caso y no me gusta que me peguen" (Nadia, 7 años, 27 de mayo de 2010). Así, se aprecia cómo la violencia tiende a generar más violencia y que aquellos que la sufren como víctimas experimentan malestar: "es feo que te digan así... Tonta o lenta y que los amigos te peguen" (Rocío, 9 años, 20 de mayo de 2010).

Estos niños repitentes perciben que sus pares les atribuyen expectativas altas y bajas en relación a la realización de tareas áulicas y del comportamiento esperado en el aula: "Que si me porto mal y me reta la seño, pero que me porto mejor este año y que escribo mejor y leo bien... No sé... Que termine rápido así me copian” (María, 9 años, 14 de mayo de 2010).

\section{- Representaciones de las docentes y de los alumnos repitentes sobre las comunicaciones en el aula}

Las representaciones del primer grupo de docentes sobre las comunicaciones en el aula se inscriben en la misma línea que sus representaciones sobre las relaciones. Así, se centran en la promoción de la participación igualitaria de los niños y en los reforzamientos positivos y públicos de los aciertos, especialmente los de los niños repitentes; una maestra decía: "Trato de que todos participen por igual, pero con los repitentes los aliento más, les doy más espacios para que puedan expresarse (...), intento reconocer sus logros ante los compañeros para que se sientan bien, que ellos pueden" (Isabel, 10 años de docencia, 16 de marzo de 2010).

Además, las docentes señalan la existencia de comunicaciones entre los actores educativos que pueden describirse como pseudo-multidireccionales, ya que a pesar de que declaran que los niños intervienen de manera igualitaria, son ellas las que conducen y autorizan 
las posibilidades de participación: "Yo trato de que los chicos trabajen juntos, que se ayuden, de que todos tengan oportunidad de responder a las preguntas que hago, así tienen protagonismo" (Rita, 10 años de docencia, 12 de marzo de 2010).

En contraste, los niños repitentes perciben que las docentes privilegian las comunicaciones unidireccionales, las intervenciones de los niños categorizados como "buenos alumnos" y que tienden a reforzar negativamente sus intervenciones:

"La seño...ella pregunta y contestamos y hay que levantar la mano para contestar y ella dice quien contesta y a mí no me elige porque dice que me hago la graciosa y digo cualquier cosa (...) Lorena dice más cuando la seño pregunta, pero yo me paro y grito para que escuche y ella me dice que no grite que no es sorda" (Maira, 9 años, 4 de junio de 2010).

Las docentes del segundo grupo sitúan sus representaciones sobre las comunicaciones en el aula, en la misma línea que las representaciones sobre las relaciones áulicas. En este sentido, por un lado, señalan la participación de todos los alumnos y los reforzamientos positivos a los aciertos y, por el otro, reconocen la existencia de reforzamientos negativos a los errores e intervenciones espontáneas poco pertinentes y el establecimiento de comunicaciones unidireccionales a fin de favorecer la participación y la focalización atencional de todos los niños en las actividades propuestas: "Si a veces pido que me respondan algunos chicos en especial, cuando están muy calladitos o molestando... Para que vuelvan a la clase" (Carina, 6 años de docencia, 12 de mayo de 2010).

En este caso último caso, la imposición de normas respondería, al igual que las comunicaciones unidireccionales, a la necesidad de establecer algún tipo de orden en la clase que ajuste los comportamientos de los niños a las expectativas vinculares positivas.

En la misma dirección, los niños repitentes señalan comunicaciones unidireccionales y reconocen reforzamientos positivos y negativos hacia sus intervenciones: "la seño pregunta y si sé la respuesta la digo, y se pone contenta porque dice que cuando yo contesto es porque le presto atención y no ando molestando, y si no sé también digo y si está mal la seño me dice que no conteste cualquier cosa, que piense" (Francisco, 9 años, 2 de abril de 2010). 


\section{- Representaciones de los niños repitentes sobre la imagen de sí en relación}

\section{a lo escolar}

Las representaciones y expectativas docentes, las representaciones y expectativas percibidas en los pares, y el tipo de relaciones que éstas determinan, parecen incidir en la configuración de la imagen de sí de los niños en relación a lo escolar. De este modo, los alumnos repitentes del primer grupo, poseen una autoimagen predominantemente negativa en relación a los escolar: "Y como mal... Mal alumno, se portamos mal (...) Rubén y yo, conversamos y molestamos en la clase (...) yo le pego con la regla y él me corretia ${ }^{8}$ (...) Mal alumno, me porto mal y no hago siempre la tarea en el grado y se me lo ensucia el cuaderno" (Kevin, 9 años, 17 de mayo de 2010).

Por su parte, los alumnos repitentes del segundo grupo tienen una imagen de sí más benigna que los del grupo anterior, la cual conjuga aspectos favorables y desfavorables: "soy un alumno, más o menos, hay cosas que hago bien (...) eso de poner la fecha y el nombre y leer a veces y (...) cosas que mal, mal, me porto mal en el grado" (Darío, 9 años, 14 de junio de 2010).

En ambos casos, las descripciones de sí que hacen los niños repitentes resultan significativas, ya que en ellas se pueden apreciar las nominaciones simbólicas que realizan las instituciones y las figuras significativas del entorno, y cómo éstas dejan huellas en la subjetividad y contribuyen a formar aquello que nombran. Es decir, que, dichas nominaciones configuran la autovalía o la imagen de sí de los alumnos (Kaplan y Kantarovich, 2005).

\section{- Representaciones de docentes y alumnos repitentes sobre las normativas}

Las principales normas explícitas o formales enunciadas tanto por las docentes como por los alumnos repitentes son: "no insultar a los compañeros ni a la señorita, no golpear a los compañeros y tampoco a la señorita, no ir al baño, no comer durante la clase" (Docentes y alumnos de $1^{\circ}$ grado) (Montero y Huertas, 2001; Postic, 2000).

Las docentes del primer grupo evidencian una contradicción: declaran propiciar una participación igualitaria, una aplicación de las normas explícitas equitativa y, a la vez, destacan que imponen estas normas a fin de garantizar el orden áulico: "las normas las impongo yo, sino

8 Corretia: referido al verbo correr. 
no se puede trabajar, es un desorden" (Isabel, 10 años de docencia). Esto fue justificado por las maestras indicando que las normas aprendidas en el hogar no resultan útiles en la escuela.

Por su lado, los niños repitentes señalan que la aplicación de normas recae principalmente en ellos y que, muchas veces, esto se justifica: "siempre me reta a mí, siempre, y a veces no me porto tan mal... Y sí me porto mal y me retan, pero no todos los días" (Kevin, 9 años, 10 de mayo de 2010). Asimismo, indican que las docentes apelan a otros mecanismos para llamar su atención, que Kaplan (2008) conceptualizó como: generalizaciones que particularizan: "La seño dice los de ahí atrás no molesten y pone cara de mala y me dice a mí nada más" (Agustín, 9 años, 8 de junio de 2010), y miradas que sancionan: "Y la seño se enoja y mira así (muestra como mira la docente) y hay que quedarse sentado y callado" (Paola, 9 años, 11 de junio de 2010).

Asimismo, las docentes del segundo grupo, también indicaron que ellas imponen las normas explícitas o formales y que la aplicación es equitativa, lo cual se contrapone al principio de reforzamiento señalado -según el cual los niños repitentes son sancionados positiva y negativamente de acuerdo a la pertinencia de las intervenciones- y a la viabilidad de las intervenciones espontáneas declarada (Montero y Huertas, 2001; Postic, 2000).

En contraposición, los niños repitentes de este grupo indicaron una aplicación diferencial de las normas explícitas que los desfavorece: "siempre me reta a mí y los chicos no" (Rocío, 7 años, 20 de mayo de 2010), y la aplicación de lo que se denominó miradas que sancionan: "si la seño te mira mucho es que te portás mal, mal" (Darío, 9 años, 14 de junio de 2010) (Kaplan, 2008)

Cabe señalar que, tanto en el primer como en el segundo grupo de docentes, la imposición de las normas explícitas o formales y la utilización de otros medios simbólicos -como las generalizaciones que particularizan o las miradas que sancionan- estarían al servicio del establecimiento de lo que Foucault (1987) denominó mecanismos de ordenamiento 0 disciplinamiento. Estos mecanismos permitirían a las docentes vigilar y controlar la conducta de los alumnos, castigando aquellas que no se ajustan a las normas establecidas. Se trataría, pues, de dispositivos de poder que también posibilitarían a estas docentes mantener su imagen de buenas enseñantes.

Por parte de los niños repitentes, la percepción que tienen sobre la desigual aplicación de las normas explícitas y de los mecanismos implícitos de control, les da a conocer sus posibilidades y sus limitaciones en relación con el docente y con los pares, de forma más o 
menos velada. Esto influye en la conformación de su autoimagen en relación con lo escolar y en la naturalización de las representaciones sobre lo escolar.

\section{- Modalidades de comunicación docente- niño repitente}

En las observaciones de clase se apreciaron diferencias en relación con las docentes y con los niños repitentes del primer grupo y del segundo grupo, respectivamente. En el caso de las docentes del primer grupo, se observa un predominio de comunicaciones unidireccionales, en las cuales las docentes hacen las preguntas o solicitan las intervenciones a los alumnos.

En general, las preguntas son dirigidas, en primer lugar, a aquellos niños categorizados como buenos alumnos o con buen rendimiento y, luego, a los otros niños, incluyendo a los repitentes. Las intervenciones espontáneas de los niños repitentes son reforzadas negativamente a partir de verbalizaciones que señalan los errores, de generalizaciones que particularizan, de miradas que sancionan negativamente, de indiferencia ante los comentarios y acciones, y de coacciones de tipo físico: "iListo! ¡Te he dicho que dejés de hacerte el gracioso contestando cualquier cosa! La docente toma al niño del brazo y lo coloca mirando a la pared, a la par del pizarrón".

En éste último caso, se aprecia una situación de violencia física, donde la docente se sitúa como agresora y el niño como víctima, lo cual produce malestar éste último, ya que, posteriormente, y ante el descrédito sufrido frente a los pares y por parte de una figura de autoridad, se niega a participar nuevamente y se limita a quedarse sentado en su silla (Abramovay y Das Graças Rua, 2005).

Cuando, ante intervenciones dirigidas por la docente, las respuestas de los niños repitentes son erróneas, las docentes los sancionan negativamente corrigiendo sus errores públicamente. Las intervenciones o respuestas acertadas no siempre son reconocidas por las maestras y cuando lo hacen, los niños repitentes reaccionan con apatía. Esto daría cuenta de que la ausencia de reconocimiento, por parte del docente, podría constituirse en una forma de violencia silenciosa, que socavaría la posibilidad de los niños repitentes de reconocer sus logros y disfrutarlos como un aspecto positivo de la imagen de sí (Abramovay y Das Graças Rua, 2005; Postic, 2000).

Las docentes del segundo grupo, en cambio, si bien privilegian las comunicaciones unidireccionales, son capaces de autorizar el diálogo entre los niños y, ocasionalmente, las intervenciones espontáneas. Cuando las docentes dirigen las preguntas, generalmente lo hacen 
intentando no escoger siempre a los mismos niños, alternando entre aquellos categorizados como "buenos alumnos" y aquellos categorizados como "malos alumnos o repitentes". En general, las intervenciones espontáneas de los niños repitentes son sancionadas negativamente, justificando esto en que: "contestan cualquier cosa, lo primero que se les pasa por la cabeza para llamar la atención" (Carina, 6 años de docencia, 27 de mayo de 2010); "Son indisciplinados y por eso se distraen, entonces dicen cualquier cosa" (Paola, 6 años de docencia, 31 de mayo de 2010).

Las sanciones negativas se realizan a partir de verbalizaciones dirigidas y públicas que desestimaban las respuestas erradas:

"No eso no es así, pensá antes de contestar"; "no, fijate bien los que estás diciendo... No contestés cualquier cosa, pensá bien lo que vas a decir"; "le pedía a Gloria que conteste, no a vos... Dejá que tu compañera también participe, respeten los turnos y no, esa no es la respuesta, pensá bien, no te apurés".

Asimismo, apelan a otros medios simbólicos como las generalizaciones que particularizan: "Chicos, los de ahí, dejen de hacerse los graciosos, todos piensen antes de contestar lo que les pregunto, no contesten cualquier cosa"; "No contesten todos al mismo tiempo porque no se entiende nada"; y las miradas que sancionan desfavorablemente. Sin embargo, las intervenciones espontáneas acertadas, también son reconocidas ocasionalmente por las docentes a partir de verbalizaciones explícitas: "Muy bien eso es, muy bien"; "Correcto, sí, muy bien".

Cuando las intervenciones solicitadas por las docentes son respondidas correctamente por los niños repitentes, esto es reconocido y ponderado públicamente por las enseñantes: "Muy bien, muy bien (...) ¿todos han escuchado lo que ha respondido Nahuel?, jeso es!". Ante estos reconocimientos docentes, los niños repitentes reaccionan positivamente expresando alegría y conformidad, lo cual daría cuenta del deseo de reconocimiento por parte de las docentes, en tanto figuras investidas de autoridad, como una forma de restitución hacia la autoimagen en relación con lo escolar (Postic, 2000). Las intervenciones solicitadas erróneas son corregidas públicamente también, a veces con verbalizaciones dirigidas y otras a partir de generalizaciones que particularizan. 


\section{- Modalidades de comunicación niños repitentes pares}

En el caso de los niños, se observa la cooperación entre pares repitentes y no repitentes al realizar las tareas asignadas por la docente, a pesar de que las docentes tendieran a agrupar a los niños repitentes cerca de su escritorio o en las primeras filas en la parte anterior del grado.

Los niños del primer grupo tienden a ser sancionados negativamente por sus pares cuando intervienen espontáneamente o cuando responden erróneamente a las preguntas de la docente. Ante estas situaciones los niños repitentes reaccionan intentando ser reconocidos tanto por la docente como por sus pares, reiterando la respuesta y, ante una nueva negativa, evitando participar o respondiendo con agresiones verbales hacia sus pares: "Callate, yo digo si quiero la respuesta, no te metás o en el recreo te patio". Sin embargo, cuando los niños repitentes son sancionados positivamente por sus pares al intervenir acertadamente, expresan entusiasmo y complacencia.

Ambas cuestiones muestran cómo los niños anhelan ser reconocidos y estimados por sus pares, lo cual resulta relevante, ya que la mirada de los pares construye la autoimagen de estos niños en relación con lo escolar (Postic, 2000; Schlemenson, 1996). Se aprecia, también, que las reiterados sanciones negativas por parte de las docentes generan sanciones similares por parte de los pares, lo cual evidenciaría una asimetría de poderes al favor de las maestras que les permitiría definir la situación y construir o modelar las representaciones de sus alumnos (Tenti Fanfani, 2004).

Los niños del segundo grupo son sancionados positiva y negativamente por sus pares al realizar intervenciones espontáneas. Los reforzamientos positivos se aprecian cuando las docentes no intervienen desautorizando la participación de los niños repitentes, y los negativos cuando las docentes señalan como inapropiadas o erróneas las intervenciones. Las sanciones negativas consisten, generalmente, en burlas por parte de los pares: "Es que a vos no te da la cabeza, sos duro"; "Vos siempre contestás mal, sos lento", que en algunos casos son sancionadas negativamente por las docentes: "Esteban! Eso que has hecho es feo, está mal burlarse de los compañeros, todos podemos equivocarnos". Sin embargo, en la generalidad de los casos, estas burlas pasan desapercibidas para las maestras o generan indiferencia como respuesta.

Ante esto, los niños repitentes reaccionan intentando llamar la atención de sus pares y de las docentes, lo cual es sancionado negativamente por los pares, si las docentes lo hacen de previo. Cuando esta situación se repite muchas veces los niños comienzan a evidenciar 
malestar: si la docente se muestra indiferente, los niños evitan seguir participando expresando tristeza en sus rostros ante el maltrato sufrido o, reaccionan con agresiones verbales y en menos ocasiones físicas, hacia sus compañeros, las cuales son respondidas, dando lugar a situaciones conflictivas en el aula que finalizaban sólo cuando las docentes interviene.

Esto muestra que el reconocimiento de los pares resulta significativo y que el mismo depende del reconocimiento por parte de las docentes, lo cual permite visualizar cómo las representaciones de los niños acerca de lo aceptable e inaceptable son construcciones sociales donde las representaciones de las figuras de poder, las docentes, poseen gran incidencia (Postic, 2000; Kaplan 2008). Cuando los niños repitentes son sancionados positivamente por sus pares, al intervenir o responder, de manera acertada, expresan entusiasmo y orgullo por la muestra de aceptación de sus compañeros. Esto evidenciaría la posibilidad de estos niños de aceptar los elogios como una parte positiva de su autoimagen en relación con lo escolar (Postic, 2000).

\section{- Aplicación de las normas en clase}

En relación al primer grupo, la aplicación de las normas explícitas o formales recae predominantemente en los niños repitentes, y son utilizadas por las docentes para poner de manifiesto las faltas cometidas por estos niños e intentar regular sus comportamientos (Postic, 2000). Ante esto, los niños repitentes, en algunos casos, acatan el mandato de las docentes manifestando vergüenza por los constantes señalamientos y, en otros, reaccionan con apatía o con agresiones verbales $\mathrm{y} / \mathrm{o}$ físicas hacia las docentes.

En general, el clima de las clases es tenso, dados los constantes esfuerzos de las docentes por coaccionar a los niños para mantener un orden impuesto, lo cual se ve dificultado, principalmente, por las intervenciones de los pares y, secundariamente, por las de los niños repitentes (Montero y Huertas, 2001). En estas interacciones de clase se puede apreciar, también, la puesta en juego de normas de carácter implícito o informal, derivadas de la distancia que los alumnos toman con las normas formales y de la aplicación más o menos coherente y flexible que hace el docente de éstas últimas (Postic, 2000).

Algunas de las normas implícitas o informales son: preferencia docente por las intervenciones solicitadas (docente pregunta-alumno responde) y espontáneas de aquellos alumnos rotulados como los mejores; mecanismos de control no verbales dirigidos a los niños repitentes como las miradas que sancionan y las generalizaciones que particularizan; 
prerrogativas a los buenos alumnos para comer en clase, charlar e ir al baño; indiferencia hacia las intervenciones de los niños repitentes como una forma de descrédito e inhibición; mal comportamiento (por ejemplo: burlas hacia los pares, juegos en clase, escaparse del grado) de los niños repitentes como una forma de llamar la atención de las docentes y de los compañeros; reacciones por parte de los niños con violencia física ante agresiones de tipo verbal, especialmente cuando involucran insultos hacia ellos, sus madres o hermanas, no reforzadas negativamente por las docentes.

En el caso del segundo grupo, la aplicación de normas explícitas o formales es más equitativa. Las docentes señalan las faltas de los niños repitentes y no repitentes a fin de regular sus comportamientos. Ante esto, los niños repitentes, en algunas ocasiones, aceptan el señalamiento realizado por las docentes y, en otras, no lo hacen y reaccionan con agresiones verbales o físicas. El clima de estas clases es más ordenado y menos tenso que el de las anteriores, ya que la alternancia en la aplicación de normas recae en el grupo de niños en general.

En este caso se identifican como normas implícitas o informales: concesiones a los buenos alumnos para charlar $\mathrm{e}$ ir al baño durante las clases; preferencia docente por las intervenciones espontáneas de aquellos alumnos rotulados como los mejores; ocasional uso de mecanismos de control no verbales dirigidos a los niños repitentes como las miradas que sancionan y las generalizaciones que particularizan; posibilidad de los niños repitentes de intervenir espontáneamente siendo ponderados por el docente y por los pares.

\section{- Organización del espacio áulico}

Las docentes del primer grupo ubican a los niños repitentes en la parte de posterior del aula, lo cual les permite interactuar principalmente con los niños ubicados en la parte delantera que son los categorizados como "buenos alumnos", dejando en un segundo plano a los niños ubicados en la parte final del salón. Esta disposición espacial, es justificada por las docentes haciendo referencia a la necesidad de que: "no haya diferencias entre los repitentes y sus pares (...) si los siento en los bancos de adelante puede ser que piensen que es para controlarlos mejor a ellos que a los otros chiquitos (...) y puede que se sientan mal por eso".

Las docentes privilegiaban las comunicaciones dirigidas con los niños ubicados en la parte delantera y manifiestan cierta indiferencia hacia los niños ubicados en la parte final del salón. Si bien esta disposición facilita las interacciones de los niños repitentes con sus pares, 
los problemas de las docentes para comunicarse con ellos dificultan la focalización atencional de los niños en las actividades propuestas. En última instancia, el agrupamiento de los niños, en la parte posterior del aula, posibilita las interacciones unidireccionales y solicitadas entre las docentes y los niños repitentes, desestimando las intervenciones espontáneas de estos niños a través de la indiferencia hacia éstas.

En el caso de las docentes del segundo grupo, la ubicación de los niños repitentes, agrupados en la parte delantera del aula o cerca del escritorio de la docente, facilita las comunicaciones unidireccionales, generando cierta dependencia y rigidez en las interacciones: las docentes controlan y autorizan las intervenciones en clase y sancionan negativamente los intercambios con los pares, argumentando que se trata de "molestar en clase". Sin embargo, los niños son capaces de ir más allá de esta modalidad de relación con las docentes, interactuando con sus pares al realizar las actividades propuestas. Ante estas situaciones las docentes reaccionan, en un primer momento, reforzando negativamente estas iniciativas, pero luego permitiendo los intercambios entre los niños.

En ambos casos son las docentes quienes decidieron de antemano la organización del espacio áulico, no pudiendo elegir los niños que lugar ocupar ni con qué compañeros sentarse.

\section{Discusiones}

El propósito de este trabajo fue reconstruir las representaciones de las docentes y de los estudiantes repitentes, escogidos para este estudio, sobre la repitencia y sus implicancias en las relaciones áulicas en el primer grado de dos escuelas periurbanas de San Miguel de Tucumán. Se aprecia que las representaciones de los actores educativos inciden en sus comportamientos y en sus relaciones. Las representaciones docentes parecen tener un peso significativo en la conformación de las representaciones de los niños repitentes, en las relaciones entre los sujetos educativos y en la organización del espacio áulico. De este modo, se identificaron dos agrupamientos de docentes y de niños repitentes que diferían en sus representaciones.

Las docentes del primer grupo poseen representaciones en las que coexisten aspectos contradictorios. La concepción asociacionista sobre la educación y la repitencia, la descripción de un vínculo asimétrico y dependiente con los niños repitentes, la imposición de normativas y los hechos de violencia en los cuales los niños repitentes son señalados como agresores; 
contrastan con la promoción de una participación igualitaria en las clases y las altas expectativas atribuidas a estos niños.

Por su parte, en el caso los niños repitentes del primer grupo, se observan los efectos de los actos de nominación docente en la conformación de las representaciones. Éstas se caracterizan por el predominio de connotaciones negativas: la repitencia como un hecho perjudicial, las actividades escolares como aburridas y reiterativas, las docentes como malas y gritonas, la percepción de las bajas expectativas que sus docentes y sus pares les atribuyen, el malestar en las relaciones áulicas derivado, principalmente, de los hechos de violencia física y simbólica por parte de las docentes, la preferencia docente por las intervenciones de los "buenos alumnos", la aplicación de normas explícitas e implícitas principalmente sobre ellos. El único aspecto positivo que perciben es el reconocimiento ocasional por parte de sus compañeros de clase.

En tanto la asimetría de poderes favorece a las maestras, como señala Tenti Fanfani (2004), les permitiría definir la situación e influir en las representaciones y comportamientos de sus alumnos. En este sentido, en las interacciones áulicas predominan las comunicaciones unidireccionales, en las cuales las docentes privilegian a los niños categorizados como buenos alumnos y sancionan negativamente las intervenciones espontáneas de los niños repitentes, en muchos casos, a través de violencia física, verbal y silenciosa.

Asimismo, los pares sancionan negativamente las intervenciones espontáneas o las respuestas erróneas a las preguntas de la docente, situaciones que terminaban generando violencia entre los niños o apatía en los niños repitentes. La aplicación de las normas explícitas o formales recae predominantemente en los niños repitentes, ante lo cual reaccionan con apatía o con agresiones verbales y/o físicas hacia las docentes. Las normas implícitas o informales surgidas en clase tienden a marcar diferencias entre los niños repitentes y los "buenos alumnos", lo cual a veces da lugar a respuestas que involucraban hechos violentos.

Las representaciones inciden también en una organización del espacio áulico en la que la ubicación de los niños repitentes en la parte de atrás del aula, permite a las docentes interactuar principalmente con los "buenos alumnos" ubicados en la parte delantera y facilita las interacciones unidireccionales y dirigidas con los niños repitentes. Aunque esta disposición posibilita las interacciones de los niños repitentes con sus pares, dificulta las comunicaciones con las docentes. 
En la misma línea que los hallazgos de Postic (2000) y Perreneaud (1996) sobre la incidencia de las representaciones docentes en las relaciones áulicas, se ha encontrado que la relevancia de las representaciones docentes se evidencia en: la influencia de las representaciones docentes negativas sobre la repitencia en la conformación de representaciones desfavorables sobre el hecho de repetir en los niños; en cómo dichas representaciones inciden en la configuración de las interacciones áulicas -siendo que, las modalidades comunicacionales y la aplicación poco equitativa de las normas son confirmadas y reproducidas por los pares dando lugar a escenas de violencia-; y en cómo la organización del espacio áulico permite la puesta en juego de estas representaciones.

La persistencia de estas situaciones incide, negativamente, en las posibilidades de los niños repitentes de reconocer sus logros y disfrutarlos como una parte positiva de la imagen de sí, es decir, que contribuyen a la formación de una autoimagen negativa en relación con lo escolar. Cabe señalar que, este tipo de relaciones donde prima el control por parte de las docentes, les permitiría mantener una imagen de sí satisfactoria, ya que, al privilegiar las respuestas de los "buenos alumnos" y autorizar o desautorizar las intervenciones de los niños repitentes verían satisfechas sus expectativas en cuanto al rendimiento escolar de los niños.

Las docentes del segundo grupo se representan a la educación y a la repitencia como fenómenos en los que intervienen diferentes factores, lo cual daría cuenta de cierto reconocimiento de la complejidad inherente a los mismos. Cabe señalar, el hecho de que estas docentes puedan atribuirse parte de la responsabilidad por las dificultades de sus alumnos y de ponerse en el lugar de ellos, ya que la reflexión acerca de las representaciones y sus implicancias permitiría la constitución de una imagen de sí en relación con el oficio docente más benigna que la de las docentes del grupo anterior. Sin embargo, la imposición de normas a fin de controlar las relaciones en el aula, las descripciones negativas sobre los niños repitentes y la dificultad para explicarse los hechos de violencia se presentan como cuestiones a repensar.

Las posibilidades de las docentes de construir a los alumnos con sus palabras, se evidencian en las representaciones de los niños repitentes que conjugan, al igual que las de sus docentes, aspectos positivos y negativos: el hecho de repetir y lo escolar como cuestiones favorables y desfavorables a la vez, las docentes adjetivadas como buenas y malas, las bajas y altas expectativas percibidas en las docentes y en los pares, la percepción del reconocimiento por parte de las docente y de los pares, la objeción hacia los hechos de violencia verbal y silenciosa, el reconocimiento de comunicaciones áulicas unidireccionales, las sanciones 
negativas y positivas por parte de los actores educativos y una aplicación poco equitativa de las normativas explícitas e implícitas que suele desfavorecerlos.

En este caso, se observa también, cómo las representaciones inciden en los comportamientos de los sujetos educativos. Las docentes, a diferencia del grupo anterior, si bien privilegian las comunicaciones unidireccionales, pueden ocasionalmente, autorizar el diálogo entre los niños y las intervenciones espontáneas. Las docentes y los pares sancionan negativa y positivamente las intervenciones espontáneas y solicitadas de los niños repitentes. Los reforzamientos positivos se aprecian cuando las docentes no intervienen desautorizando la participación de los niños repitentes, y los negativos cuando señalan como inapropiadas o erróneas las intervenciones. Cuando los reforzamientos negativos se hacen constantes dan lugar a la apatía de los niños repitentes hacia las docentes y a hechos de violencia verbal y física entre pares.

La aplicación de normas explícitas, en este caso, es más equitativa que el grupo anterior, lo cual incide positivamente en las relaciones entre los actores educativos, ya que se observan menos escenas de violencia verbal y física entre pares. Se identifican como normativas implícitas: las preferencias docentes por las intervenciones espontáneas de los "mejores alumnos" y el ocasional uso de mecanismos de control no verbales dirigidos a los niños repitentes. Las representaciones docentes dan lugar a una organización del espacio áulico en la que los niños repitentes se encuentran ubicados en la parte delantera del aula y/o cerca del escritorio de la docente. Esto permite las comunicaciones unidireccionales docentealumno repitente, generando a veces cierta dependencia y rigidez en las interacciones. Sin embargo, los niños son capaces de ir más allá de esta modalidad comunicacional e interactuar con sus pares.

En la misma dirección que lo propuesto por Perreneaud (1996) y Postic (2000), las representaciones docentes influyen en la conformación de las representaciones de los niños repitentes sobre la repitencia, las cuales involucran aspectos favorables y desfavorables; en la configuración de interacciones áulicas, en las que se dan comunicaciones uni y multidireccionales, en una aplicación de normas explícitas e implícitas más equitativa y en una organización del espacio áulico que, si bien parece favorecer un mayor control docente, facilita las relaciones entre los actores educativos.

La capacidad de las docentes de reconocer su responsabilidad en las dificultades de los niños y ponerse en el lugar de ellos, la confluencia de aspectos positivos y negativos en las 
representaciones y expectativas de las docentes y de los pares y el tipo de relaciones a las que dan lugar influyen en la configuración de una imagen de sí más positiva que la de los niños repitentes del grupo anterior, ya que ésta conjuga aspectos favorables o reparadores y aspectos desfavorables. También, la autoimagen de estas docentes parece ser más benigna también, pues son capaces de reconocer sus debilidades y fortalezas en tanto enseñantes y de ser empáticas con sus aprendientes. (Ver anexo)

Estos hallazgos permitirán profundizar la investigación de esta temática indagando la configuración de las representaciones categoriales acerca de la educación, la violencia, la convivencia y sus consecuencias en las relaciones educativas. En tanto los principios de clasificación de las docentes y de los pares no son conscientes, los sujetos reproducen, sin saberlo, clasificaciones que pueden basarse en prejuicios naturalizados a nivel social.

Cuestionar las representaciones de los actores educativos resulta importante, porque lo que está en juego son las trayectorias escolares de los alumnos. Por ello, sería necesario encarar la organización de espacios de reflexión, a nivel de las instituciones escolares, que faciliten la desnaturalización de los anudamientos representacionales. Finalmente, el juicio de los expertos externos a la investigación muestra la bondad de los temas generales encontrados y de las hipótesis explicativas generadas.

\section{Referencias}

Abramovay, Miriam y Das Graças Rua, Maria. (2005). Violences in schools. Brasilia: UNESCO. Recuperado el 15 de diciembre de 2009 de http://unesdoc.unesco.org/images/0013/001339/133967e.pdf

Alliaud, Andrea y Antelo, Estanislao. (2006). Los gajes del oficio. Enseñanza, pedagogía y formación. Buenos Aires: Aique

Castorina, José Antonio y Kaplan, Carina Viviana. (2003). Las representaciones sociales: problemas teóricos y desafíos educativos. En J. A. Castorina (Comp.), Las representaciones sociales: problemas teóricos y desafíos educativos (pp. 9- 27). España: Gedisa.

Coll, César. (1996). Aprendizaje escolar y construcción del conocimiento. Buenos Aires: Paidós.

Debarbieux, Eric. (2001). A violencia na escola francesa: 30 annos de construçao social do objeto (1967/1997). Educação e Pesquisa, 27, 163- 193. 
Departamento de Estadística y Planeamiento del Ministerio de Educación de TucumánDEPMETUC. (2009). Datos de repitencia, sobreedad y desgranamiento de matrícula en la provincia de Tucumán- período 2007 a 2009- Tucumán: Ministerio de Educación Provincia de Tucumán. Recuperado el 12 de febrero de 2009 de http://www.educaciontuc.gov.ar/sistema/

Departamento de Estadística y Planeamiento del Ministerio de Educación de TucumánDEPMETUC. (2010). Informe: indicadores educativos de proceso (1998-2010). Tucumán: Ministerio de Educación Provincia de Tucumán. Recuperado el 10 de marzo de 2010 de http://www.educaciontuc.gov.ar/sistemal

Dirección Nacional de Información y Evaluación de la Calidad Educativa -DINIECE. (2007). Operativo Nacional de Evaluación 2007. Recuperado el 9 de marzo de 2010 desde http://www.me.gov.ar

Dirección Nacional de Información y Evaluación de la Calidad Educativa -DINIECE. (2008). Datos sobre repitencia, sobreedad y abandono interanual en la Argentina- período 1996/2006. Recuperado el 15 de julio de 2009 de la Base de Datos para Usuarios del DINIECE en http://diniece.me.gov.ar/

Farías, Mónica, Fiol, Dolores, Kit, Irene y Melgar, Sara. (2007) Todos Pueden Aprender. Propuestas para superar el fracaso escolar. Buenos Aires: Fondo de las Naciones Unidas para la infancia y Asociación civil educación para todos.

Foucault, Michel. (1987). Los cuerpos dóciles. En M. Foucault Vigilar y Castigar. Nacimiento de la prisión (pp. 145-163). México: Siglo XXI.

García Márquez, Nélida. (1986). Quiero aprender, dame una oportunidad. Madrid: Gedisa.

Gil Moreno, María del Carmen. (2008). Repensar la educación desde la complejidad. Publicación de la cátedra. Tucumán: Facultad de Psicología de la Universidad Nacional de Tucumán.

Gilly, Michel. (1984) Psicosociología de la educación. En S. Moscovici (Ed.) Psicología Social Tomo II. (pp. 601- 626). Barcelona: Paidós.

Gilly, Michel. (2002). As representaçoes soçiais no campo educativo. Educar, Cartibia, 19, 231 252.

Gvirtz, Silvina y Palamidessi, Mariano. (2008). El ABC de la tarea docente: currículo y enseñanza. Buenos Aires: Aique.

Hernández Sampieri, Roberto, Fernández Collado, Carlos. y Baptista Lucio, Pilar. (2008). Metodología de la Investigación. México: Ultra.

Jodelet, Denise. (1984). La representación social: fenómenos, concepto y teoría (pp. 468- 494) En S. Moscovici Psicología Social Tomo II. Barcelona: Paidós. 
Kaplan, Carina. (1997). La inteligencia escolarizada. Un estudio de las representaciones sociales de los maestros sobre la inteligencia de los alumnos y su eficacia simbólica. Buenos Aires: Miño y Dávila

Kaplan, Carina. (2008). Buenos y malos alumnos. Descripciones que predicen. Buenos Aires: Aique.

Kaplan, Carina y Kantarovich, Gabriela. (2005). La mirada del docente: un lugar simbólico para mirarse como alumno. Novedades Educativas, 170, $22-23$.

Lacasa, Pilar. (1994). Aprender en la escuela, aprender en la calle. Madrid: Visor.

Maddonni, Patricia y Aizecang, Noemí. (2000). El fracaso escolar: un tema central en la agenda educativa. En M. C. Chardon (Comp.), Perspectivas e interrogantes en Psicología Educacional (pp. 215-229). Buenos Aires: Eudeba.

Montero, Ignacio y Huertas, Juan Antonio. (2001). Modos de aprender con los demás: condiciones y alternativas. En I. Montero y J. A. Huertas (Eds.) La interacción en el aula. Aprender con los demás (151-199). Buenos Aires: Aique.

Perazza, Roxana. (2009). Notas para reflexionar sobre las políticas de inclusión en América Latina. La experiencia de los programas de aceleración de aprendizajes. Revista Iberoamericana sobre eficacia, calidad y cambio educativo, 7, (7) 264- 275. Recuperdo el 2 de noviembre de 2010 de http://www.rinace.net/reice/numeros/arts/vol7num4/art13.pdf

Pérez Gómez, Angel. (1998). La cultura escolar en la sociedad neoliberal. Madrid: Morata.

Perrenoud, Philippe. (1996). La construcción del éxito y del fracaso escolar. Hacia un análisis del éxito, del fracaso y de las desigualdades como realidades construidas por el sistema escolar. Madrid: Morata.

Postic, Marcel. (1982/2000). La relación Educativa. Madrid: Narcea.

Schlemenson, Silvia. (1996). El aprendizaje: un encuentro de sentidos. Bs. As: Kapelusz.

Tenti Fanfani, Emilio. (2001/ 2004). Sociología de la Educación. Buenos Aires: Universidad Nacional de Quilmes- Editorial. 


\section{ANEXO}

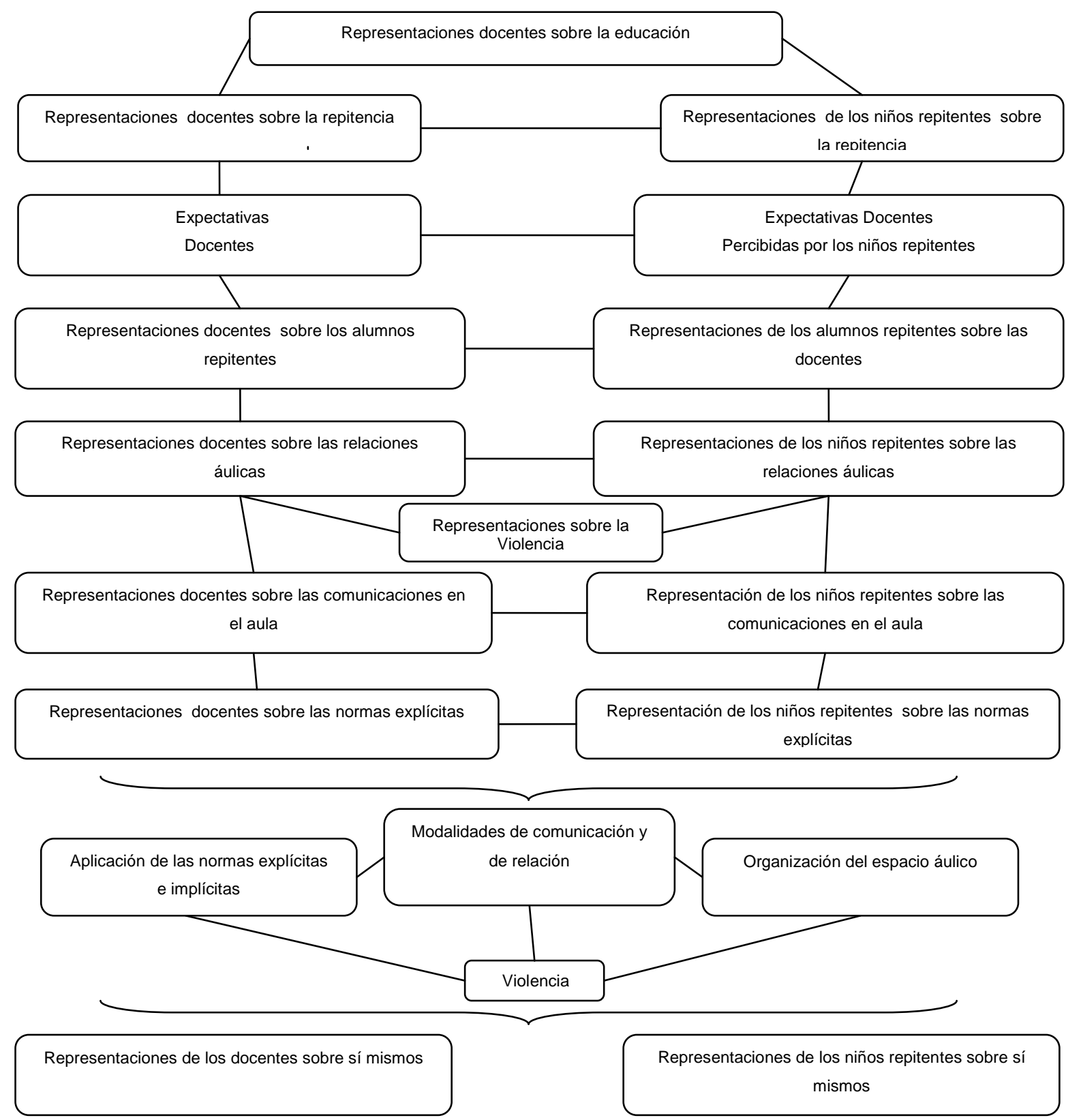

Relaciones entre las representaciones de los docentes, de los niños repitentes y sus implicaciones en las interacciones áulicas.

Fuente: Elaboración propia. 